\title{
INVENTARIO, TASACIÓN Y ALMONEDA DE LOS BIENES DE DON PEDRO CALDERÓN
}

En 1905 publicó Cristóbal Pérez Pastor, en su recopilación de Documentos para la biografía de D. Pedro Calderón de la Barca, pp. 410-429, unos manuscritos que pretendían ser "el inventario, tasación y almoneda" de las posesiones de Calderón, protocolo sacado de las particiones de bienes del escribano Juan de Burgos de 1675 a 1682 .

En realidad, lo publicado por Pérez Pastor fue sólo el inventario de los papeles que dejó el dramaturgo y la tasación de otros bienes, copia incompleta del documento original - "Inventario, tasación...", etc.-, que es hoy el legajo 8188 (sin foliación) del Archivo Histórico de Protocolos de Madrid, legajo en que se encuentran otros protocolos de Juan de Burgos, por ejemplo el inventario y tasación de los bienes del Duque de Medina de las Torres, de 1668.

El documento original permite corregir algunos errores mínimos de Pérez Pastor: la fecha de un reconocimiento de censo que él lee como " 1675 " (p. 414) es en realidad 1671; en la tasación de "16 sillas de baqueta a 4 reales cada una" (p. 427) hay que leer "cuarenta reales" (y, en consecuencia, poner 640 reales en la suma, en vez de 64). Hay, sin embargo, un error importante en el texto de Pérez Pastor. Él declara que toda la tasación se hace en reales de plata, cuando en verdad, salvo la de los artículos de plata, en que el notario anota cuidadosamente que se trata de "reales de plata", la tasación está hecha en reales de vellón. Sólo en tres casos - "una cama de granadillo", "una escribanía de ébano" y "una colgadura de damasco" - se preocupa el notario de escribir "reales de vellón", porque en esas fechas se había generalizado la costumbre de expresar así el valor de los bienes ${ }^{1}$.

${ }^{1}$ Sobre el uso constante del real de vellón en los libros de cuentas de este 
Tratándose de "reales de plata", el escribano tenía que indicar expresamente que se había apartado de la práctica general. Si no se sabe de qué clase de reales se trata, es imposible hacer una comparación entre el valor tasado y el precio que se pagó en la almoneda, el cual se calcula siempre en reales de vellón.

La almoneda es, sin duda, la sección más interesante de estos documentos calderonianos. Permite, desde luego, comparar el valor tasado con el precio pagado; nos hace saber con exactitud el monto de la herencia recibida por la Venerable Congregación de Sacerdotes Naturales de Madrid (a la cual dejó Calderón todo el dinero obtenido en la almoneda) y apreciar el grado de entusiasmo despertado en el público por las obras de arte que con tanto amor había coleccionado el dramaturgo: en la almoneda se hace constar quiénes compraron cuadros, láminas y esculturas, y qué cantidad pagaron ${ }^{2}$.

Calderón murió el 25 de mayo de 1681. Rápidamente, el primero de junio, sus albaceas se pusieron a hacer el inventario y la tasación, diviendo los bienes en cinco grupos: plata (tasada en 15412 reales de plata, o sea 23118 reales de vellón); pinturas y láminas (tasadas por Claudio Coello en 16965 reales de vellón), madera (tasada en 8022 reales de vellón), esculturas (2 066 reales de vellón) y colgaduras (2 983 reales de vellón). La suma total asciende a 53154 reales de vellón ${ }^{3}$. Como se ve, la plata constituía casi la mitad del valor de los bienes del dramaturgo, aunque las obras de arte (cuadros, láminas y esculturas) suman la importante cantidad de 19031 reales de vellón.

La almoneda, iniciada el 16 de junio, tuvo lugar en la misma casita de la Calle Mayor en que había muerto Calderón (es difícil

periodo véase EARL J. Hamilton, War and prices in Spain 1651-1800, Harvard University Press, Cambridge, MA, 1947, p. 10 et passim.

${ }^{2}$ Además de componer El pintor de su deshonra, Calderón es notable por la cantidad y la frecuencia de metáforas inspiradas en la pintura. El ensayo de Eunice Joiner Gates, "Calderón's interest in art”, PhQ 40 (1961), 53-67, que alude a muchos de los cuadros, láminas y esculturas inventariados por Juan de Burgos en 1681, sirve de útil introducción al tema. Helga Bauer le ha dedicado todo un libro: Der Index Pictorius Calderons. Untersuchungen zu seiner Malereimetaphorik, de Gruyter, Hamburgo, 1969.

${ }^{3}$ Antes de 1680 , el real de plata había llegado a evaluarse en un $275 \%$ más que el de vellón. El decreto desinflacionario del 10 de febrero de ese año redujo drásticamente la diferencia: el real de plata pasó a evaluarse en sólo un $50 \%$ más que el de vellón, y esto se mantuvo hasta 1686 . Véase HamiLTON, op. cit., tabla 1 y p. 31 . 
imaginar cómo cabían tantas cosas en tan corto espacio . Anunció los bienes Juan Galeano, pregonero público, bajo la mirada de Juan Díaz Mariño, tesorero de la Congregación de Sacerdotes, quien recogía al final de cada sesión la cantidad de dinero producida por la almoneda. Aunque el precio de unos pocos objetos se da en reales de plata, la suma de cada día se calcula en reales de vellón.

No fue el de 1681 un año que dejara esperar grandes ganancias de una almoneda. La desinflación de 1680 había causado una depresión económica que afectaba a todos los sectores de la economía, haciendo de este periodo el peor para España desde la peste del siglo XIv ${ }^{5}$. Hubo almoneda en 21 de los días que van del 16 de junio al 11 de julio. El primer día arrojó la suma más importante (23 044 reales de vellón), producto, principalmente, de la venta a Francisco de la Cruz, vecino de Córdoba, de casi la totalidad de la plata (1 579 onzas). Las piezas adquiridas por Francisco de la Gruz se habían tasado en 19247 reales de vellón (casi 12.2 reales por onza), pero él no pagó sino $18958 \frac{1}{2}$ reales. Siendo la plata lo que más atraía a los compradores, era ya de preverse que el producto de la almoneda no sería gran cosa. Se transparenta la decepción en las palabras del escribano: toda esa plata, dice, se remató a 12 reales la onza "por no haber quien diese más por ella". Por extraño o triste que hoy nos parezca, toda la plata, lisa o cincelada - con pájaros, flores, conchas-, se evaluó exclusivamente por su peso, lo mismo en la tasación que en la almoneda.

En vista de que durante varios días no llegó el producto ni a 100 reales, y que en cuatro días no se presentó nadie a la almoneda, la Congregación decidió suspenderla después del 11 de julio, "por escusar los gastos tan grandes que se seguían [a la hacienda de Calderón]". El 9 de agosto el tesorero Juan Díaz Mariño declaró con juramento que había logrado vender por cuenta propia algunos otros objetos, y ese día se dio por terminado el asunto. Los bienes habían sido tasados en 53154 reales de vellón, pero la Congregación no obtuvo sino 33768 , y conservó únicamente cuatro de los objetos inventariados, a los cuales nos referiremos en seguida.

Las pinturas, láminas y esculturas se vendieron, en general, por poco más de la mitad del valor tasado, y a veces por menos.

${ }^{4}$ Ramón de Mesonero Romanos, El antiguo Madrid, Mellado, Madrid, 1861 , p. 80 y nota, habla de la incomodidad y estrechez de esta morada.

5 Véase Hamilton, op. cit., pp. 127-135. 
Así, un cuadro del Descendimiento de la Cruz, evaluado en 770 reales de vellón, se vendió en 400; las 18 láminas de piedra de la historia de Nuestra Señora, evaluadas en 2376 reales de vellón, fueron compradas en 1440 por un tal Francisco Martínez; el licenciado Joseph de Gayeta pagó 1500 reales por tres cuadros: un San Pedro y un San Pablo (tasados en 880) y una Cena grande, con marco dorado (tasada en 3000 , y sin duda uno de los cuadros predilectos de Calderón, pues estaba en su oratorio).

La Congregación de Sacerdotes se quedó con una escribanía tasada en 800 reales de vellón, con un Santo Cristo de madera, tasado en 400, con un Niño durmiendo, de pasta, tasado en 66, y, quizá a propósito y por gusto, con un San Francisco en éxtasis, "pintura de Italia", tasado en 3300 reales. Era el único cuadro que Claudio Coello había identificado como de pintor italiano y, tal vez por eso, el de valor más alto.

Los intentos de seguir la pista de este cuadro han sido infructuosos. Era posible que la Congregación lo hubiera conservado a lo largo de tres siglos, o que, por lo menos, sus Libros de Acuerdos y Actas hubieran anotado su venta y su paradero. Desde 1902 la Congregación se halla instalada en los números 101 y 103 de la Calle de San Bernardo, adonde en ese mismo año fueron llevados los restos de Calderón ${ }^{6}$. Pero ha pasado demasiado tiempo, ha habido demasiados motines y trastornos sociales, en una palabra, demasiada historia. En el verano de 1936, durante los ataques contra el clero y los templos de Madrid, la iglesia de la Congregación sufrió saqueo e incendio. Desapareció la urna que, según se creía, encerraba las cenizas del dramaturgo; desaparecieron los Libros de Acuerdos, salvo uno solo; y nadie recuerda ahora nada sobre el "San Francisco en éxtasis, pintura de Italia".

Willard F. King

Bryn Mawr College

${ }^{6}$ Fue ésa la quinta traslación de sus restos, según el informe detallado de Emilio Cotarelo y Mori, Ensayo sobre la vida y obras de D. Pedro Calderón de la Barca, Revista de Archivos, Bibliotecas y Museos, Madrid, 1924, pp. 363-371. 